\title{
The Affordable Care Act: policy predictors of integrated care between Hispanic- serving and mainstream mental health organizations
}

\author{
Robert Rosales ${ }^{1 *}$ (i) and Rocío Calvo ${ }^{2}$
}

\begin{abstract}
Background: The Patient Protection and Affordable Care Act increased funding for integrated care to improve access to quality health care among underserved populations. There is evidence that integrated care decreases inequities in access and quality of mental health care among Hispanic clients. Increasing integrated care at Hispanic-Serving Organizations may help to eliminate mental health service disparities among Hispanic clients.

Method: Using organizational responses from the 2014 and 2016 waves of the National Mental Health Service survey, this study conducted multivariate logistic analyses to assess whether the ACA policies related to integrated care increased the provision of integrated addictions treatment and primary care at mental health Hispanic-Serving Organizations, relative to Mainstream Organizations.

Results: Findings showed that Hispanic-Serving Organizations (54.4\%) were less likely to provide integrated health services than Mainstream Organizations (59.1\%) after the ACA. However, federal funding to help organizations transition into integrated care services (AOR $=1.74, p=0.01$ ) and accepting Medicaid payments $(A O R=1.59, p=$ 0.01) increased the provision of integrated care services at Hispanic-Serving Organizations over time.
\end{abstract}

Conclusions: Health care policies that increase funding to adopt integrated health services at community HispanicServing Organizations may help decrease inequities in mental health access for Hispanics in the United States.

Keywords: Hispanics, Integrated care, Affordable care act, Community health centers, Hispanic-serving organizations

\footnotetext{
* Correspondence: Robert_rosales@brown.edu

${ }^{1}$ Department of Behavioral \& Social Sciences, Center for Alcohol and

Addictions Studies, Brown University School of Public Health, 121 South

Main Street, 4th Floor, Providence, RI 02903, USA

Full list of author information is available at the end of the article
}

(c) The Author(s). 2021 Open Access This article is licensed under a Creative Commons Attribution 4.0 International License, which permits use, sharing, adaptation, distribution and reproduction in any medium or format, as long as you give appropriate credit to the original author(s) and the source, provide a link to the Creative Commons licence, and indicate if changes were made. The images or other third party material in this article are included in the article's Creative Commons licence, unless indicated otherwise in a credit line to the material. If material is not included in the article's Creative Commons licence and your intended use is not permitted by statutory regulation or exceeds the permitted use, you will need to obtain permission directly from the copyright holder. To view a copy of this licence, visit http://creativecommons.org/licenses/by/4.0/ The Creative Commons Public Domain Dedication waiver (http://creativecommons.org/publicdomain/zero/1.0/) applies to the data made available in this article, unless otherwise stated in a credit line to the data. 


\section{Background}

Research shows that there are persistent disparities in health care services between Hispanic-Serving Organizations (HSOs) and Mainstream Organizations (MOs) [1, 2]. HSOs, defined as organizations with more than $20 \%$ of Hispanic clients [3], tend to score low in accessibility and quality of health care [4]. Integrated care, a collaborative model of health care delivery, has been shown to increase healthcare quality among Hispanic clients [5]. However, less than one-third of HSOs provide integrated health care [3]. Increasing the provision of integrated care at HSOs may ameliorate disparities in access to quality health care among Hispanics [5].

The Patient Protection and Affordable Care Act (ACA) promoted the adoption of integrated care to increase the quality of health care that Americans receive. To that end, the ACA fostered the integration of mental health care into primary care and into addictions treatment, and increased funding for health care organizations that wished to adopt integrated services [6]. Little is known about the effect of these measures on Hispanic-Serving Organizations (HSOs).

\section{Integrated health care and mental health care among Hispanic clients}

Integrating addictions treatment and primary care into mental health care is a practical approach to increasing access to quality mental health care among Hispanics, especially for those with serious mental illness [5, 7-9]. Integrated care is a collaborative model of health care delivery that involves multiple levels of collaboration. Rather than merely placing physical and behavioral health clinicians in the same setting, integrated care encourages multidisciplinary teams' cooperation in the creation of assessments, interventions, and the delivery of services. Therefore, integrating mental health services into primary care settings and into addiction services helps address barriers associated with referrals, transportation, cost, and the difficulties associated with scheduling various services at multiple locations [10].

This collaborative way of providing health care has shown promise in decreasing disparities in access to mental health care among Hispanic clients by normalizing the use of behavioral health [11]. Bridges and colleagues [5] found that Hispanic clients who received behavioral services in integrated settings experienced reduced mental health symptoms at a similar rate as non-Hispanic whites. Participants also reported high levels of satisfaction with the quality of care experienced in integrated care settings. These findings suggest that integrated care may reduce inequities in access to quality mental health care for Hispanic clients.

Integrated health care and the Affordable Care Act (ACA) The ACA intended to increase access to quality health care, including mental health care, among underserved populations. To this end, the ACA: (1) provided funding to community health centers to facilitate the adoption of integrated care, and (2) increased access to health care by expanding Medicaid eligibility.

To facilitate the adoption of integrated care, the ACA created two major grants. The first grant assigned $\$ 105.8$ million to the Health Resources and Services Administration (HRSA) to assist community health care centers in providing integrated health care services to populations with severe physical and mental illnesses [12]. The second grant established the $\$ 11$ billion Community Health Centers Fund (CHCF), which helped increase community health centers' capacity to provide integrated care [13]. This CHCF's primary purpose was to assist community health centers with the infrastructure, processes, and staff necessary to transition into integrated health care services [14].

The expansion of the criteria to qualify for Medicaid was the chief strategy to increase health coverage among populations that lacked health insurance, including Hispanics. However, some states challenged the mandatory expansion of Medicaid, which led the Supreme Court to declare it optional [15]. By 2014, the year in which the ACA had to be fully implemented, only 25 states had adopted the expansion of Medicaid [16]. The discrepancy in available Medicaid funds between expansion and non-expansion states created a fractured system, where organizations in expansion states benefited from a larger pool of Medicaid payments than organizations in nonexpansion states. As a result, health care organizations in expansion states saw a decrease in uncompensated care stemming from an increase in Medicaid coverage of low-income patients [17-20]. Extra funds incentivized mental health care organizations in expansion states to invest in the transition to integrated care. Additionally, mental health care organizations could use new bundled Medicaid payments for integrated care. For instance, organizations could adopt Medicaid bundled payments for a package of services that included both behavioral and physical health care [21, 22]. Health care organizations took advantage of the ACA's new bundled payments option, which allowed them to be reimbursed for a package of services rather than charge services separately.

\section{Aim of the study}

The ACA promoted mental health care integration into primary care and into addictions treatment to increase access to quality health care. It is unknown how these provisions impacted HSOs. The current study investigates: 1) Whether the provision of integrated primary care and addictions treatment increased in HSOs between 2014 and 2016, and 2) The impact of the ACA measures for the promotion of integrated care in HSOs. 


\section{Methods}

\section{Study Design \& Survey Tool}

We conducted multivariate logistic regression analyses with secondary cross-sectional data from the 2014 and 2016 National Mental Health Services Survey (NMHSS). The N-MHSS is a publicly available national census of mental health organizations in the US. The N-MHSS, which has been conducted annually since 2014, uses paper, web-based, and telephone-assisted questionnaires to gather organizations' clients, structure, and service characteristics. The N-MHSS does not collect data from military treatment facilities, jails or prisons, residential treatment facilities without specialty behavioral services, and individual and small group practices not licensed as mental health clinics $[23,24]$.

\section{Sample}

We selected the 2014 and 2016 waves of the $\mathrm{N}$ MHSS because they are the only publicly available data waves that included the ethnoracial characteristics of the population served at the mental health organizations. The Center for Behavioral Health Statistics and Quality (CBHSQ) of the Substance Abuse and Mental Health Services Administration (SAMHSA), and the US Department of Health and Human Services requested all their private and public mental health organizations throughout the 50 US states to take part in the N-MHSS. Each organization's directors completed the 2014 N-MHSS survey between March 2014 and January 2015 and the 2016 N-MHSS between March 2016 and January 2017.

In terms of inclusion and response rate, $88.1 \%$ of the 16,687 organizations identified in 2014 completed the survey. Over $10 \%$ of the organization were excluded afterward because they only provided administrative services, were included in other organization counts, or were determined to be out-of-scope by the survey administrators. Of the 13,983 organizations identified in 2016, 91.1\% completed the survey, and $4.1 \%$ were excluded afterward because they only provided administrative services or were included in other organization counts. The current study excluded 5732 organizations because they did not report their Hispanic population, which resulted in a final analytic sample of 19,314 organizations. The analytical sample included 9857 organizations from the 2014 N-MHSS and 9457 from the 2016 N-MHSS.

Unique case identifiers for each of the organizations were not publicly available. Therefore, we used a repeated cross-sectional design to merge both waves into one dataset, which is an established method to combine multiple waves of data into a single dataset when there are no unique identifiers [25].

\section{Dependent variables Integrated health care}

We used two variables to assess whether the mental health organizations provided integrated addictions treatment and integrated primary care. The first variable derived from a question that captured whether organizations provided any of 14 mental health treatments using the following question, "Which of these mental health treatment modalities are offered at this facility, at this location?" Organizations that reported providing integrated substance use treatments were coded as (1), while organizations that did not report this service were coded as $(0)$. The second variable was derived from a question that captured whether organizations provided any of 26 services using the following question, "Which of these services and practices are offered at this facility, at this location?" Organizations that reported providing integrated primary care services were coded as (1), while organizations that did not report this service were coded as (0).

\section{Independent variables ACA measures}

Federal Grants Organizations were asked to respond to the following question: "Which of the following types of client payments, insurance, or funding are accepted by this facility for mental health treatment services?" The federal grants variable used responses on this question to capture whether organizations (1) received, or (0) did not receive these community mental health block grants. Community mental health block grants were defined as funding from a Health Resources and Services Administration (HRSA) grant or Community Health Centers Fund (CHCF) grant.

Organization in an expansion state Using Medicaid expansion state data from the Kaiser Family Foundation [16], a variable was created that measured whether organizations were located in Medicaid (1) expansion or (0) non-expansion states.

Organizations take Medicaid payments This variable, taken from the N-MHSS survey, captured whether the organizations accepted Medicaid payments. Responses were coded as (1) Yes, or (0) No.

\section{Control variables}

Each model included a set of client and organizational characteristics. The ownership variable categorized organizations into (0) public, (1) private non-profit, and (2) private for-profit. We also adjusted for whether organizations were community mental health centers (1) Yes, or (0) No; and for their outpatient size, which captured the total number of clients served at the organization in 
April of the year the data was collected. Outpatient size ranged from 0 (none) to 12 (more than 1500). In terms of the characteristics of the clients served at each organization annually, we controlled for the percentage of children (individuals 17 years or younger), adults (individuals between 18 to 64 years of age), and older adults (people 65 years and older), as well as for the percentage of female clients. Client characteristic variable responses ranged from 0 (none) to 7 (More than 75\%).

\section{Data analysis}

We conducted a three-step data analysis using Stata, Statistical Software 15.1. First, we used prior literature on ethnoracial minority-serving organizations to categorize organizations into HSOs (i.e., more than $20 \%$ Hispanic clients) and MOs (i.e., 20\% or fewer Hispanic clients) [3]. We included MOs in the models because comparing the findings for HSOs and MOs allows for a better understanding of the ACA's impact on providing integrated addictions treatment and primary care at HSOs. On a second step, we conducted a series of bivariate analyses to assess potential differences between HSOs and MOs concerning the study's variables. The third step consisted of two sets of multivariate logistic analyses. The first set of regressions identified the predictors associated with providing integrated addictions treatment at mental health HSOs and MOs. The second set of regressions identified the predictors related to providing integrated primary care at mental health HSOs and MOs. Each set of regressions was conducted separately for HSOs and MOs. We calculated adjusted odds ratios (AOR) by controlling for the remaining predictor variables (Medicaid expansion, Medicaid payments accepted, community mental health block grant, and year), and for control variables (ownership, community mental health center, organization size, $\%$ youth, $\%$ adults, $\%$ older adults, and \% female served annually).

\section{Interaction terms}

Interactions assessed whether the ACA's impact in the provision of integrated care 1) was different in expansion versus non-expansion states, and 2) changed from 2014 to 2016. Each interaction model was run separately and adjusted by controlling for the main effects of the predictor variables (Medicaid expansion, Medicaid payments accepted, community mental health block grant, year) and of the control variables (ownership, community mental health center, organization size, \% youth, \% adults, \% older adults, and \% female served annually).

\section{Results}

\section{Characteristics of the sample}

Preliminary findings from this study were reported elsewhere [26]. Table 1 reports the sample characteristics for the HSOs and MOs and the bivariate analysis results. MOs were significantly more likely to provide integrated addictions services than HSOs, $\chi^{2}(1, N=19,244)=21.65$, $p<0.001$. Specifically, $59.1 \%$ of MOs provided integrated addictions services relative to $54.4 \%$ of HSOs. No significant differences emerged between HSOs and MOs concerning the provision of integrated primary care.

Turning to the association between the ACA measures and the provision of integrated care, MOs were more likely (42.9\%) than HSOs (38.2\%) to receive federal block grants for the adoption of integrated care, $\chi^{2}(1, N=15,345)=16.61$, $p<0.001$. By contrast, almost $78 \%$ of HSOs were located in expansion states relative to $57 \%$ of MOs, $\chi^{2}(1, N=19,314)=$ $420.43, p<0.001$. No significant differences emerged between HSOs and MOs concerning the acceptance of Medicaid payments, $\chi^{2}(1, N=18,923)>0.01, p=0.978$.

Concerning the control variables, more MOs (29.8\%) than HSOs (25.1\%) self-identified as community health centers, $\mathrm{X}^{2}(1, N=19,314)=26.04, p<0.001$. HSOs were larger and served more youth than MOs, concentrating on adult, older adult, and female clients. In terms of ownership, HSOs were more likely to be non-profit organizations, while MOs were more likely to be for-profit organizations.

\section{Integrated addictions services in mental health care organizations}

Table 2 presents the logistic regression analyses findings concerning the association between the ACA measures and the provision of integrated addiction services. We observed a significant decrease in the provision of integrated addictions care both at HSOs $(\mathrm{AOR}=0.69, p<0.001)$ and MOs $(\mathrm{AOR}=0.77, p<0.001$ ) from 2014, the year the ACA was implemented, to 2016. HSOs and MOs had 31 and $23 \%$ lower odds, respectively, of providing integrated addictions treatment 2 years after implementing the ACA.

In terms of the association between the ACA measures and integrated addictions services, results showed that HSOs $(\mathrm{AOR}=1.60, p<0.001)$ and $\mathrm{MOs}(\mathrm{AOR}=1.75, p<0.001)$ that received federal block grants were more likely to transition into integrated care. Whether organizations were located or not in expansion states was not significantly associated with integrated care provision. By contrast, accepting Medicaid payments increased the chances of providing integrated addictions services at $\mathrm{HSOs}(\mathrm{AOR}=1.59, p=$ $0.005)$, but not at MOs (AOR $=1.01, p=0.859$ ).

Concerning interaction effects, after controlling for main effects and control variables, we observed significant differences only on the impact of the ACA measures over time. There was a significant decrease in the provision of integrated services in MOs located in expansion states $(\mathrm{AOR}=0.85, p=0.002)$. MOs in expansion states had 15\% lower odds in 2016 than in 2014 of providing integrated addictions services. By contrast, community mental health HSOs had $74 \%$ greater odds 
Table 1 Sample characteristics stratified by Hispanic-serving (HSO) and Mainstream organizations (MO) $(N=19,314)$

\begin{tabular}{|c|c|c|c|c|c|}
\hline \multirow[t]{2}{*}{ Variables } & \multicolumn{2}{|c|}{$\mathrm{HSO}(\mathrm{N}=2803)$} & \multicolumn{2}{|c|}{$\mathrm{MO}(N=16,511)$} & \multirow[t]{2}{*}{$p$-values } \\
\hline & $n$ & $\%$ & $n$ & $\%$ & \\
\hline \multicolumn{6}{|l|}{ Integrated Care Variables } \\
\hline \multicolumn{5}{|l|}{ Integrated addictions treatment } & \multirow[t]{3}{*}{$<0.001$} \\
\hline Yes & 1520 & 54.4 & 9725 & 59.1 & \\
\hline No & 1273 & 45.6 & 6726 & 40.9 & \\
\hline \multicolumn{5}{|l|}{ Integrated primary care } & \multirow[t]{3}{*}{0.549} \\
\hline Yes & 619 & 22.2 & 3734 & 22.7 & \\
\hline No & 2166 & 77.8 & 12,686 & 77.3 & \\
\hline \multicolumn{6}{|l|}{ ACA Provisions } \\
\hline \multicolumn{5}{|l|}{ Medicaid expansion } & \multirow[t]{3}{*}{$<0.001$} \\
\hline Expansion state & 2174 & 77.6 & 9418 & 57.0 & \\
\hline Non-expansion state & 629 & 22.4 & 7093 & 43.0 & \\
\hline \multicolumn{5}{|l|}{ Medicaid payments accepted } & \multirow[t]{3}{*}{0.978} \\
\hline Yes & 2501 & 91.0 & 14,706 & 90.9 & \\
\hline No & 249 & 9.0 & 1467 & 9.1 & \\
\hline \multicolumn{5}{|l|}{ Community mental health block grants } & \multirow[t]{3}{*}{$<0.001$} \\
\hline Yes & 845 & 38.2 & 5630 & 42.9 & \\
\hline No & 1365 & 61.8 & 7505 & 57.1 & \\
\hline \multicolumn{6}{|l|}{ Control Variables } \\
\hline \multicolumn{5}{|l|}{ Community mental health center } & \multirow[t]{3}{*}{$<0.001$} \\
\hline Yes & 703 & 25.1 & 4923 & 29.8 & \\
\hline No & 2100 & 74.9 & 11,588 & 70.2 & \\
\hline \multicolumn{5}{|l|}{ Ownership } & \multirow[t]{5}{*}{$<0.001$} \\
\hline Public/other & 537 & 19.2 & 3312 & 20.1 & \\
\hline Private non-profit & 1970 & 70.3 & 10,398 & 63.0 & \\
\hline \multirow[t]{3}{*}{ Private for-profit } & 296 & 10.5 & 2801 & 16.9 & \\
\hline & \multicolumn{2}{|l|}{ HSO } & \multicolumn{2}{|l|}{$\mathrm{MO}$} & \\
\hline & \multicolumn{2}{|c|}{ M [Category ${ }^{\mathrm{a}}$ (SD) } & \multicolumn{2}{|c|}{ M [Category $\left.{ }^{\mathrm{a}}\right](\mathrm{SD})$} & $p$-values \\
\hline Organization size & \multicolumn{2}{|c|}{7.7 [101 to 250$](2.8)$} & \multicolumn{2}{|c|}{7.4 [76-100] (2.9) } & $<0.001$ \\
\hline$\%$ Youth clients & \multicolumn{2}{|c|}{3.6 [31 to $40 \%](2.8)$} & $2.8[21$ & & $<0.001$ \\
\hline$\%$ Adult clients & $4.5[4]$ & & $5.3[41$ & & $<0.001$ \\
\hline$\%$ Older adult clients & $0.9[1$ & & $1.2[1 \mathrm{tc}$ & & $<0.001$ \\
\hline$\%$ Female clients & $5.1[41$ & & $5.2[41$ & & $<0.001$ \\
\hline
\end{tabular}

Notes. Percentages are presented for nominal variables and means and standard deviations for ordinal/continuous variables. All variables were included in 2014 and 2016 N-MHSS. Mental-health Hispanic-serving organizations = more than $20 \%$ of Hispanic clients; Mainstream organizations $=20 \%$ or fewer of Hispanic clients ${ }^{a}$ Categories were determined by rounding the decimal to the nearest whole number

of providing integrated addictions services in 2016 than in $2014(\mathrm{AOR}=1.74, p=0.010)$.

Integrated primary care in mental health care organizations Table 3 presents the findings for the logistic regression analysis for the provision of integrated primary care services. Results showed no significant change from 2014 to 2016 in the provision of integrated primary care services at HSOs $(\mathrm{AOR}=1.23, p=0.068)$ or at $\mathrm{MOs}(\mathrm{AOR}=0.98, p=.674)$.
Turning to the impact of the ACA measures on the provision of integrated primary care services, HSOs $(\mathrm{AOR}=1.97, p<0.001)$ and $\mathrm{MOs}(\mathrm{AOR}=1.26, p<$ 0.001 ) that received federal funding in the form of community mental health block grants were more likely to provide integrated primary health care services. Additionally, MOs that accepted Medicaid payments were significantly less likely to offer integrated primary care services $(\mathrm{AOR}=0.59, p<0.001)$. 
Table 2 Logistic regression analysis on integrated addictions treatment stratified by HSOs and MOs (2014 to 2016)

\begin{tabular}{|c|c|c|c|c|c|c|}
\hline & \multicolumn{3}{|c|}{ Hispanic-serving Organizations $(N=2159)$} & \multicolumn{3}{|c|}{ Mainstream Organizations $(N=12,502)$} \\
\hline & $\overline{A O R}$ & $95 \% \mathrm{Cl}$ & $p$-value & $\overline{A O R}$ & $95 \% \mathrm{Cl}$ & $p$-value \\
\hline \multicolumn{7}{|l|}{ Year } \\
\hline 2016 & 0.69 & $0.58-0.83$ & $<0.001$ & 0.77 & $0.72-0.83$ & $<0.001$ \\
\hline Medicaid expansion & 0.99 & $0.78-1.24$ & 0.898 & 0.93 & $0.86-1.00$ & 0.062 \\
\hline Medicaid payments accepted & 1.59 & $1.15-2.19$ & 0.005 & 1.01 & $0.89-1.15$ & 0.859 \\
\hline Community mental health block grant & 1.60 & $1.31-1.94$ & $<0.001$ & 1.75 & $1.61-1.90$ & $<0.001$ \\
\hline \multicolumn{7}{|l|}{ Medicaid Expansion Interaction Terms } \\
\hline Medicaid expansion x Medicaid payments accepted & 1.09 & $0.50-2.37$ & 0.831 & 1.16 & $0.91-1.47$ & 0.242 \\
\hline Medicaid expansion x CMHC & 1.45 & $0.90-2.32$ & 0.129 & 0.87 & $0.74-1.02$ & 0.080 \\
\hline Medicaid expansion x CMHBG & 1.25 & $0.80-1.95$ & 0.321 & 1.01 & $0.86-1.17$ & 0.939 \\
\hline \multicolumn{7}{|l|}{ Time Interactions } \\
\hline Medicaid expansion × 2016 & 0.68 & $0.44-1.05$ & 0.077 & 0.85 & $0.73-0.98$ & 0.028 \\
\hline Medicaid payments accepted $\times 2016$ & 0.68 & $0.36-1.27$ & 0.224 & 0.84 & $0.66-1.06$ & 0.141 \\
\hline $\mathrm{CMHC} \times 2016$ & 1.74 & $1.14-2.66$ & 0.010 & 0.89 & $0.76-1.05$ & 0.159 \\
\hline CMHBG $\times 2016$ & 1.38 & $0.95-2.02$ & 0.095 & 0.90 & $0.78-1.05$ & 0.177 \\
\hline
\end{tabular}

Note. AOR Adjusted Odds Ratio. All models accounted for control (ownership, organization size, community mental health center, \% youth, \% adults, \% older adults, and \% female), Medicaid expansion (Medicaid expansion, Medicaid payments accepted, Community mental health block grant), and time variables. Interaction models controlled for all main effects, including control variables. Interaction terms were conducted separately from each other. Year: 2010 is the reference category. Ownership: public departments is the reference categories. CMHC Community mental health center, CMHBG Community mental health block grant

After controlling for main effects and control variables, the interaction terms between Medicaid expansion and the ACA measures showed that HSOs in expansion states that accepted Medicaid payments were more likely to provide integrated primary care services $(\mathrm{AOR}=3.16, p=0.014)$. Turning to the interaction on the impact of the ACA over time, after adjusting for main effects and control variables, HSOs that received community mental health block grants had greater odds of providing integrated primary care 2 years after the implementation of the ACA $(\mathrm{AOR}=$ $1.79, p=0.010$ ).

Table 3 Logistic regression analysis on integrated primary care stratified by HSOs and MOs (2014 to 2016)

\begin{tabular}{|c|c|c|c|c|c|c|}
\hline & \multicolumn{3}{|c|}{ Hispanic-serving organizations $(N=2173)$} & \multicolumn{3}{|c|}{ Mainstream organizations $(N=12,944)$} \\
\hline & AOR & $95 \% \mathrm{Cl}$ & $p$-value & AOR & $95 \% \mathrm{Cl}$ & $p$-value \\
\hline \multicolumn{7}{|l|}{ Year } \\
\hline 2016 & 1.23 & $0.99-1.53$ & 0.068 & 0.98 & $0.90-1.07$ & 0.674 \\
\hline Medicaid expansion & 0.89 & $0.68-1.16$ & 0.371 & 1.00 & $0.91-1.10$ & 0.983 \\
\hline Medicaid payments accepted & 1.10 & $0.72-1.69$ & 0.664 & 0.59 & $0.51-0.69$ & $<0.001$ \\
\hline Community mental health block grant & 1.97 & $1.57-2.49$ & $<0.001$ & 1.26 & $1.14-1.39$ & $<0.001$ \\
\hline \multicolumn{7}{|l|}{ Medicaid Expansion Interaction Terms } \\
\hline Medicaid expansion $\times$ Medicaid payments accepted & 3.16 & $1.26-7.93$ & 0.014 & 0.90 & $0.69-1.17$ & 0.437 \\
\hline Medicaid expansion x CMHC & 1.42 & $0.83-2.43$ & 0.199 & 0.95 & $0.79-1.15$ & 0.610 \\
\hline Medicaid expansion x CMHBG & 1.08 & $0.65-1.80$ & 0.775 & 1.24 & $1.04-1.49$ & 0.017 \\
\hline \multicolumn{7}{|l|}{ Time Interactions } \\
\hline Medicaid Expansion $\times 2016$ & 0.62 & $0.37-1.02$ & 0.061 & 0.99 & $0.82-1.18$ & 0.868 \\
\hline Medicaid payments accepted $\times 2016$ & 1.15 & $0.50-2.62$ & 0.742 & 0.97 & $0.74-1.26$ & 0.804 \\
\hline $\mathrm{CMHC} \times 2016$ & 1.43 & $0.89-2.30$ & 0.145 & 1.10 & $0.91-1.33$ & 0.312 \\
\hline CMHBG $\times 2016$ & 1.79 & $1.15-2.79$ & 0.010 & 0.97 & $0.81-1.16$ & 0.729 \\
\hline
\end{tabular}

Note. AOR Adjusted Odds Ratio. All models accounted for control (ownership, organization size, community mental health center, $\%$ youth, $\%$ adults, $\%$ older adults, and \% female), Medicaid expansion (Medicaid expansion, Medicaid payments accepted, Community mental health block grant), and time variables. Interaction models controlled for all main effects, including control variables. Interaction terms were conducted separately from each other. Year: 2010 is the reference category. Ownership: public departments is the reference categories. CMHC Community mental health center, CMHBG Community mental health block grant 


\section{Discussion}

To increase the quality of health care in the US, the Patient Protection and Affordable Care Act (ACA) promoted the adoption of integrated care. To that end, the ACA fostered the integration of mental health care into primary care and addictions treatment, and increased funding for health care organizations that wished to adopt integrated services. This study investigated: 1) whether integrated care after the ACA increased in HSOs relative to MOs 2) the impact of the ACA measures for the promotion of integrated care in HSOs relative to MOs.

Trends in integrated care at HSOs and MOs after the ACA Results showed a significant decrease in the provision of integrated addictions treatment in HSOs and MOs 2 years after implementing the ACA. No significant differences were observed in the provision of integrated primary care between organizations. The decrease in the provision of integrated addictions treatment may be in response to challenges in implementing the reform. Health care organizations reported problems stemming from inadequate funding, technology gaps, and shortages of trained integration clinicians [27]. For instance, there is evidence that the greater cost of providing care to individuals with serious comorbid illnesses prevented organizations from adopting and keeping integrated models of care after the ACA [13]. Integrated health care settings require costly new systems to handle the provision of care, as well as systemic changes in organizational structures to process insurance claims and payments [28]. These changes forced some organizations to assume the burden of costly staff training, making the provision of integrated care unsustainable [21, 22].

\section{Differences in the trends in integrated care between HSOs and MOs}

While there was a decrease in the provision of integrated addictions treatment at MOs and HSOs after the ACA, the decline was substantially larger for HSOs. This is consistent with prior research on integrated care disparities between HSOs and MSOs [1, 2]. Specifically, less than a third of HSOs nationwide provide integrated mental health and addictions treatment services, relative to almost half of MOs [3]. Providing integrated substance use care increases the demand for professionals who can provide these services. Yet, there is a shortage of clinicians trained to provide integrated addictions services [29], especially among Spanish-speaking clients who have enormous difficulties finding ethnic-concordant providers who can provide services in Spanish [30]. Yet, there is evidence that substance misuse deaths have increased since the ACA's adoption [31-34]. Marijuana use rates among Hispanic youth, one of the central populations served at HSOs, have significantly increased in the last few years $[35,36]$. Although integrated care may decrease disparities concerning access to quality mental health care among Hispanic clients [5], they are significantly less likely to live near organizations that provide integrated care [37]. Barriers to integrated care is a critical issue among Hispanics with severe mental illness who have historically faced limitations with overall access to care.

\section{ACA provisions to increase access to integrated care}

Accepting Medicaid payments and receiving block grants were associated with increased provision of integrated addictions treatment at HSOs. These findings align with prior evidence showing that organizations accepting Medicaid payments have financially benefitted from the increase in insured clients [19]. Medicaid payments account for more than $25 \%$ of mental health services in the US. Meanwhile, the bundled payments adopted with the ACA provided new opportunities for the integration of addictions treatment in mental health care organizations [38]. With the reimbursement from these new payment methods, HSOs can provide evidence-based integrated care, including transition care [38]. Before the ACA, several obstacles made it difficult for mental health care organizations to charge for integrated services. Health insurance providers, including State Medicaid Plans, did not allow health care organizations to bill for more than one type of services (e.g., behavioral and primary care) within the same day $[39,40]$. This forced organizations not to bill Medicaid, turning instead to private insurers to cover these integrated services [41].

Our interaction terms showed that over time HSO community mental health centers were more likely to adopt integrated addictions services and integrated primary care. Similarly, HSOs that accepted Medicaid payments and that were in Medicaid expansion states increased integrated primary care provision. This suggests that the ACA's strategy of facilitating the payment of integrated services through increased federal funding for HSOs community health centers that wished to adopt an integrated care infrastructure was effective. Community mental health block grants have increased since the implementation of the ACA [42]. Our findings suggest that this funding helps close the gap on the provision of integrated care at HSOs.

\section{Limitations}

Notwithstanding the strengths of this study, some limitations should be considered. First, since the N-MHSS did not include unique case identifiers, we could not identify the number of organizations that overlapped from the 2014 to 2016 N-MHSS. Since all organizations in this study came from the same database, there may be overlap between organizations in 2014 and 2016. Second, the use of a repeated cross-sectional design precludes us from drawing causal conclusions of the findings. Third, 
health care integration is a complex system. It is a healthcare delivery method where all practitioners must learn to work within the new integrated system [43]. Our use of two general questions about integrating addictions treatment and primary care may not capture the integration level involved in healthcare settings [44]. Finally, the term HSOs does not account for other essential services that would increase access to care among Hispanic clients, such as language concordance. However, the advantage of using this term is that it allows the assessment of how the ACA increased the provision of integrated care at mental health care organizations with larger proportions of Hispanic clients, even if they do not provide culturally congruent care.

\section{Conclusion}

This study found that while HSOs provided fewer integrated behavioral health services 2 years after implementing the ACA, the federal funding allocated to help community health care centers transition into integrated care services and accepting Medicaid payments increased the provision of integrated care services at HSOs. Health care policies that help to increase funding for the adoption of integrated health services at community HSOs may help decrease inequities in access and quality of health care among Hispanics. This study helps decrease the shortage of research on how the ACA is associated with health care disparities at HSOs [45].

\section{Abbreviations}

ACA: The Patient Protection and Affordable Care Act; HSOs: Hispanic-Serving Organizations; MOs: Mainstream Organizations; PCPs: Primary care physicians; N-MHSS: National Mental Health Services Survey

\section{Acknowledgements}

We would like to thank David Takeuchi, PhD for providing mentorship throughout the writing and conceptualization of this manuscript.

\section{Authors' contributions}

RR and RC designed the study. RR conducted the data analysis, interpretation of results, and wrote the manuscript with input from RC. All authors read and revised the manuscript and approved the final version of the manuscript.

\section{Funding}

This research was supported in part by grant number T32AA007459 from the National Institute on Alcohol Abuse and Alcoholism at the National Institute of Health.

\section{Availability of data and materials}

The datasets generated during and/or analyzed during the current study are available in the Drug \& Alcohol Services Information System repository, [https://wwwdasis.samhsa.gov/dasis2/nmhss.htm].

\section{Ethics approval and consent to participate}

Since the 2014 and 2016 N-MHSS were publicly available and de-identified this research was exempt from Institutional Review Board review at Brown University.

\section{Consent for publication}

Not applicable.

\section{Competing interests}

The authors declare that they have no competing interests.

\section{Author details}

'Department of Behavioral \& Social Sciences, Center for Alcohol and Addictions Studies, Brown University School of Public Health, 121 South Main Street, 4th Floor, Providence, RI 02903, USA. 'Boston College, School of Social Work, McGuinn Hall, 140 Commonwealth Avenue, Chestnut Hill, MA 02467, USA.

Received: 23 March 2020 Accepted: 21 February 2021

Published online: 28 February 2021

\section{References}

1. Creanga AA, Bateman BT, Mhyre JM, Kuklina E, Shilkrut A, Callaghan WM. Performance of racial and ethnic minority-serving hospitals on deliveryrelated indicators. Am J Obstet Gynecol. 2014;211:647.e1-647.e16. https:// doi.org/10.1016/j.ajog.2014.06.006.

2. Rodriguez F, Joynt KE, López L, Saldaña F, Jha AK. Readmission rates for Hispanic Medicare beneficiaries with heart failure and acute myocardial infarction. Am Heart J. 2011;162:254-61. https://doi.org/10.1016/j.ahj.2011.05. 009.

3. Roth BJ, Allard SW. (re) defining access to Latino immigrant-serving organizations: evidence from Los Angeles, Chicago, and Washington, DC. J Soc Social Work Res. 2016;7:729-53. https://doi.org/10.1086/689358.

4. Jha AK, John Orav E, Epstein AM. Low-quality, high-cost hospitals, mainly in south, care for sharply higher shares of elderly black, Hispanic, and medicaid patients. Health Aff. 2011;30:1904-11.

5. Bridges AJ, Andrews AR, Villalobos BT, Pastrana FA, Cavell TA, Gomez D. Does integrated behavioral health care reduce mental health disparities for Latinos? Initial findings. J Lat Psychol. 2014;2:37-53. https://doi.org/10.1037/ lat0000009.

6. Croft B, Parish SL. Care integration in the patient protection and affordable care act: implications for behavioral health. Adm Policy Ment Heal Ment Heal Serv Res. 2013;40:258-63.

7. Corrigan PW, Pickett S, Batia K, Michaels PJ. Peer navigators and integrated care to address ethnic health disparities of people with serious mental illness. Soc Work Public Health. 2014;29:581-93.

8. Huang S, Fong S, Duong T, Quach T. The affordable care act and integrated behavioral health programs in community health centers to promote utilization of mental health services among Asian Americans. Transl Behav Med. 2016;6:309-15. https://doi.org/10.1007/s13142-016-0398-4.

9. Cabassa L, Gomes AP, Meyreles Q, Capitelli L, Younge R, Dragatsi D, et al. Primary health care experiences of Hispanics with serious mental illness: a mixed-methods study. Adm Policy Ment Heal Ment Heal Serv Res. 2014;41: 724-36.

10. Lanesskog D, Piedra LM. Integrated health care for Latino immigrants and refugees: what do they need? In: Benuto LT, O'Donohue W, editors. Enhancing behavioral health in Latino populations: reducing disparities through integrated behavioral and primary care. 1st ed. Cham, Switzerland: Springer International Publishing; 2016. p. 11-23.

11. Cabassa $\sqcup$, Hansen MC, Palinkas LA, Ell K. Azúcar y nervios: explanatory models and treatment experiences of Hispanics with diabetes and depression. Soc Sci Med. 2008;66:2413-24.

12. Substance Abuse and Mental Health Services Administration. Community mental health services block grant. 2017. https://www.samhsa.gov/grants/ block-grants/mhbg.

13. Druss BG, Mauer BJ. Health care reform and care at the behavioral health—primary care interface. Psychiatr Serv. 2010;61:1087-92. https://doi. org/10.1176/ps.2010.61.11.1087

14. Sommers BD, Gawande AA, Baicker K. Health insurance coverage and health — what the recent evidence tells us. N Engl J Med. 2017;377:586-93. https://doi.org/10.1056/NEJMsb1706645.

15. Jacobs LR, Callaghan T. Why states expand Medicaid: party, resources, and history. J Health Polit Policy Law. 2013;38:1023-50. https://doi.org/10.1215/ 03616878-2334889.

16. Kaiser Family Foundation. Status of state action on the Medicaid expasion decision. 2017. https://www.kff.org/health-reform/state-indicator/state-a ctivity-around-expanding-medicaid-under-the-affordable-care-act/ ?currentTimeframe $=0 \&$ sortModel=\%7B\%22colld\%22:\%22Location\%22,\%22 sort\%22:\%22asc\%22\%7D. Accessed 1 Jan 2017. 
17. Camilleri S, The ACA. Medicaid expansion, disproportionate share hospitals and uncompensated care. Health Serv Res. 2018;53:1562-80.

18. Corrigan P, Sheehan L, Morris S, Larson JE, Torres A, Lara JL, et al. The impact of a peer navigator program in addressing the health needs of Latinos with serious mental illness. Psychiatr Serv. 2017;69:456-61. https:// doi.org/10.1176/appi.ps.201700241.

19. Lindrooth RC, Perraillon MC, Hardy RY, Tung GJ. Understanding the relationship between Medicaid expansions and hospital closures. Health Aff. 2018:37:111-20. https://doi.org/10.1377/hlthaff.2017.0976.

20. Sharma Al, Dresden SM, Powell ES, Kang R, Feinglass J. Emergency department visits and hospitalizations for the uninsured in Illinois before and after affordable care act insurance expansion. J Community Health. 2017;42:591-7.

21. Mechanic RE. Opportunities and challenges for episode-based payment. $N$ Engl J Med. 2011;365:777-9. https://doi.org/10.1056/NEJMp1002530.

22. Centers for Medicare and Medicaid Services. BPCI Advanced. 2018. https:// innovation.cms.gov/initiatives/bpci-advanced.

23. Substance Abuse and Mental Health Services Administration. Data on Mental Health Treatment Facilities (BHSIS Series S-98, HHS Publication No. (SMA) 17-5049). Rockville; 2017.

24. Substance Abuse and Mental Health Services Administration. Data on Mental Health Treatment Facilities. (BHSIS Series S-87, HHS Publication No. (SMA) 16-5000). Rockville; 2016

25. Lebo M, Weber $C$. An effective approach to the repeated cross sectional design. Am J Pol Sci. 2015;59:242-58. https://doi.org/10.7910/DVN1/22651.

26. Rosales R. If you make it, will they come?: the impact of the affordable care act and organizational characteristics on Hispanic mental health care organizations: Boston College; 2018. http://hdl.handle.net/2345/bc-ir:108096

27. Docherty M, Spaeth-Rublee B, Scharf D, Ferenchick EK, Humensky J, Goldman ML, et al. How practices can advance the implementation of integrated care in the COVID-19 era. Washington; 2020.

28. McLellan AT, Woodworth AM. The affordable care act and treatment for "substance use disorders:" implications of ending segregated behavioral healthcare. J Subst Abus Treat. 2014:46:541-5.

29. Ghitza UE, Tai B. Challenges and opportunities for integrating preventive substance-use-care services in primary care through the affordable care act. J Health Care Poor Underserved. 2014;25(1 Suppl):36-45.

30. Ortega AN, Rodriguez HP, Vargas BA. Policy dilemmas in Latino health care and implementation of the affordable care act. Annu Rev Public Health. 2015;36:525-44. https://doi.org/10.1146/annurev-pub/health-031914-122421.

31. Atluri S, Sudarshan G, Manchikanti L. Assessment of the trends in medical use and misuse of opioid analgesics from 2004 to 2011. Pain Physician. 2014;17:E119-28.

32. Hedegaard $H$, Chen L-H, Warner M. Drug poisoning deaths involving heroin: United States, 2000-2013. Hyattsville; 2015.

33. Jones CM, Logan J, Gladden RM, Bohm MK. Vital signs: demographic and substance use trends among heroin users - United States, 2002-2013. MMWR Morb Mortal Wkly Rep. 2015;64:719-25. https:/doi.org/10.2105/AJPH.2015.302664.

34. Joseph TD. Falling through the coverage cracks: how documentation status minimizes Immigrants' access to health care. J Health Polit Policy Law. 2017; 42:961-84. https://doi.org/10.1215/03616878-3940495.

35. Johnson RM, Fairman B, Gilreath T, Xuan Z, Rothman EF, Parnham T, et al. Past 15-year trends in adolescent marijuana use: differences by race/ ethnicity and sex. Drug Alcohol Depend. 2015;155:8-15.

36. Marzell M, Sahker E, Pro G, Arndt S. A brief report on Hispanic youth marijuana use: trends in substance abuse treatment admissions in the United States. J Ethn Subst Abus. 2017;16:155-64. https://doi.org/10.1080/1 5332640.2015 .1108256

37. Guerrero EG, Kao D. Racial/ethnic minority and low-income hotspots and their geographic proximity to integrated care providers. Subst Abuse Treat Prev Policy. 2013:8:1-10.

38. Mechanic D. Seizing opportunities under the affordable care act for transforming the mental and behavioral health system. Health Aff. 2012; 31:376-82.

39. Duarte C. Community health centers and payment for integrated care. In: Benuto LT, O'Donohue W, editors. Enhancing behavioral health in Latino populations: reducing disparities through integrated behavioral and primary care. 1st ed. Cham: Springer International Publishing; 2016. p. 95-103.

40. McKinney D, Kidney R, Xu A, Lardiere MR, Schwartz R. State policy report \#34: health center reimbursement for behavioral health services in Medicaid. Washington; 2010.
41. Auxier A, Farley T, Seifert K. Establishing an integrated care practice in a community health center. Prof Psychol Res Pract. 2011:42:391-7.

42. The US Department of Health and Human Services. HHS FY 2017 budget in brief - SAMHSA. 2016.

43. Benuto LT, O'Donohue W, editors. Enhancing behavioral health in Latino populations: reducing disparities through integrated behavioral and primary care. Cham: Springer International Publishing; 2016.

44. Heath B, Wise Romero P, Reynolds K. A review and proposed standard framework for levels of integrated healthcare; 2013.

45. Santisteban D, Vega RR, Suarez-Morales L. Utilizing dissemination findings to help understand and bridge the research and practice gap in the treatment of substance abuse disorders in Hispanic populations. Drug Alcohol Depend. 2006:84(Suppl 1):S94-101.

\section{Publisher's Note}

Springer Nature remains neutral with regard to jurisdictional claims in published maps and institutional affiliations.
Ready to submit your research? Choose BMC and benefit from:

- fast, convenient online submission

- thorough peer review by experienced researchers in your field

- rapid publication on acceptance

- support for research data, including large and complex data types

- gold Open Access which fosters wider collaboration and increased citations

- maximum visibility for your research: over $100 \mathrm{M}$ website views per year

At $\mathrm{BMC}$, research is always in progress.

Learn more biomedcentral.com/submissions 